Iranian Quarterly Journal of Breast Disease 2018; 11(2):7.

\title{
Prevalence of Port-Related Infections and Their Predisposing Factors in Women with Breast Cancer under Chemotherapy
}

\author{
Khanbabayi Gol M: Nursing Education, Nursing Research Committee of Imam Reza Hospital, Tabriz \\ University of Medical Sciences, Tabriz, Iran \\ Arefi N: Nursing Education, Responsible for the Nursing Research Committee of Khatamolanbia Hospital, \\ Tabriz University of Medical Sciences, Miyaneh, Iran \\ Jafari M: Tabriz University of Medical Sciences, Tabriz, Iran \\ Farzin H: Faculty of Medicine, Tabriz University of Medical Sciences, Tabriz, Iran \\ Aghamohammadi D: Faculty of Medicine, Tabriz University of Medical Sciences, Tabriz, Iran
}

Corresponding Author: Davood Aghamohammadi, Daghamohammadi@yahoo.com

\begin{abstract}
Introduction: Awareness of the prevalence of chemotherapy port infections and the underlying factors in cancer patients is absolutely necessary, providing us with methods to help eliminate the infection in these patients the aim of this study was to determine the prevalence of port-related infections and the associated factors in women with breast cancer under chemotherapy.
\end{abstract}

Methods: A total of 73 patients undergoing chemotherapy for treatment of breast cancer were screened for signs of infection following port insertion in the subclavian area. After confirmation of the symptoms of infection, samples were sent to two laboratories for diagnosis of infection. A $\mathrm{P}$ value of $<.05$ was considered significant.

Results: Ten percent of the patients with clinical symptoms of infection were diagnosed with infection in laboratory tests. There were statistically significant differences in weight, age, the number of chemotherapy sessions, the duration of port placement, and the duration of hospitalization following port implantation between patients with infection and patients with no infection.

Conclusion: Port-related infection in patients whit breast cancer can compromise the treatment process. Therefore, achieving better treatment outcomes requires considering the duration of port implantation and use, as well as paying attention to the clinical symptoms of infection and the underlying factors.

Keywords: Breast Cancer, Chemotherapy, Port, Infection 


\section{بررسى شيوع عفونتهاى مرتبط با يورت و فاكتور هاى مستعدكننده آن در زنان مبتلا به سرطان

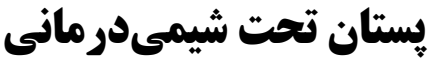

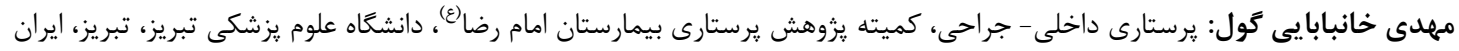

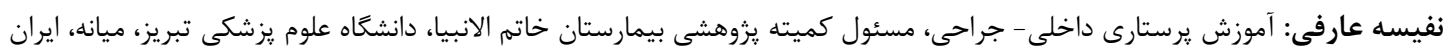

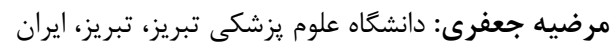

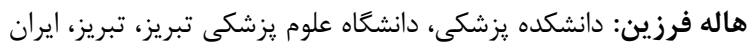

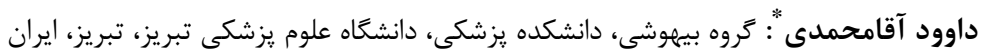

مقدمه: آكاهى از شيوع و فاكتورهاى مستعدكننده عفونت محل يورت شيمىدمانى در مبتلايان به سرطان امرى كاملا

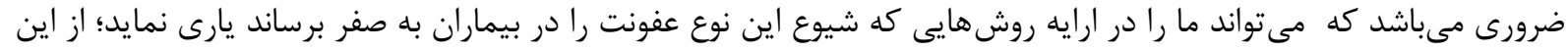

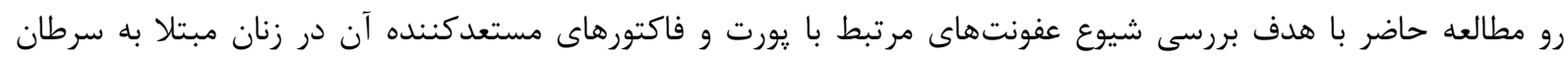
يستان تحت شيمىدرمانى انجام شد.

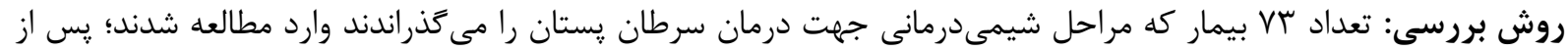

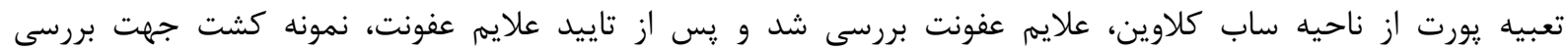

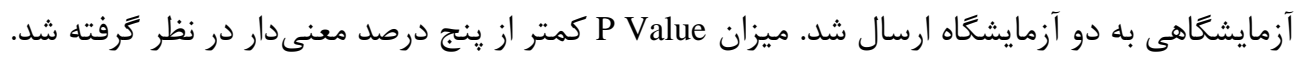

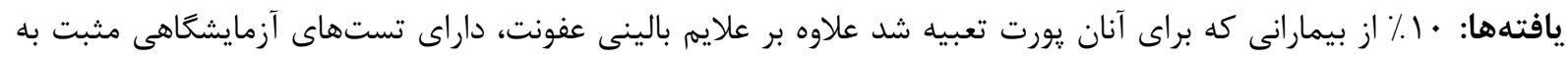

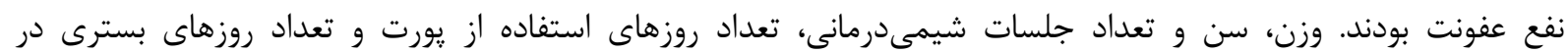

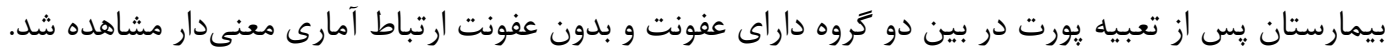

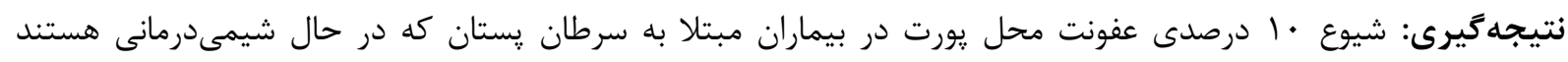

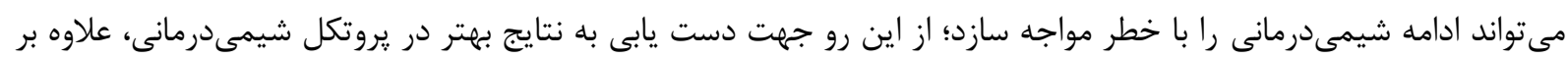

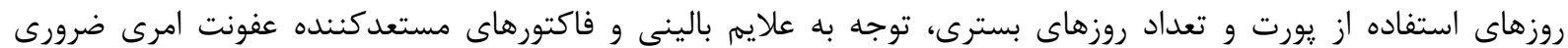


سيستم يورت علاوه بر اينكه به طور قابل توجهى رنج

درمانهاى داخل وريدى را كاهش مى دهد، موجب افزايش

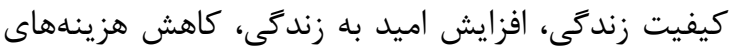

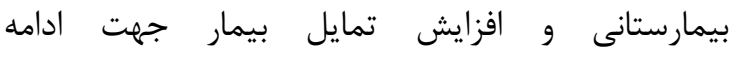
شيمىدرمانى مى كردد (T) (I). محلهاى متعددى جهت تعبيه يورت مورد استفاده قرار

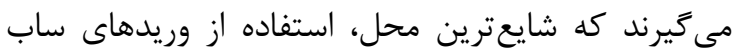
كلاوين مىباشد؛ استفاده از اين وريدها متاسفانه بان

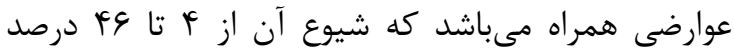

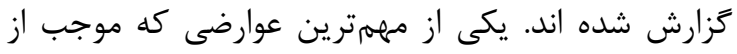

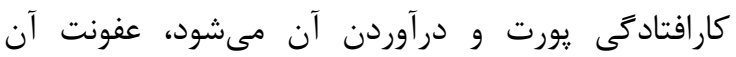
مىباشد. از اين رو بايد عوامل مستعدكننده عفونت محل

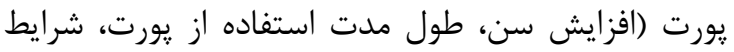

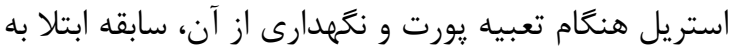
بيمارىهاى عفونى و افزايش مدت زمان بسترى درئ بيمارستان) و شيوع آن به دقت مورد بررسى قرار گيرند تا

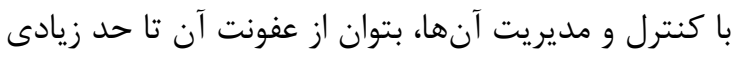

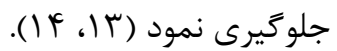
با توجه به افزايش درخواست متخصصين انكولوزى و

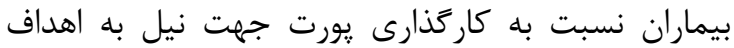
درمانى بهتر و گسترش استفاده از اين سيستم و همجنين بروز عفونت در اين سيستم كه موجب درآوردن آن آن

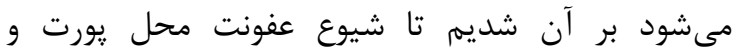

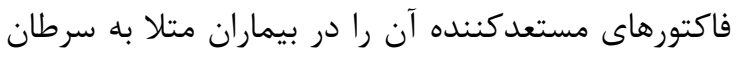

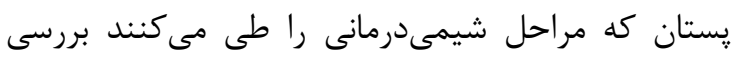
نماييم. آكاهى از شيوع و فاكتورهاى مستعدكننده عفونت

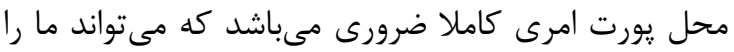
در ارايه روشهايى كه شيوع اين نوع عفونت را در بيماران به صفر برساند يارى نمايد.

\section{مواد و روشها}

در اين مطالعه توصيفى مقطعى كه در طى بازه زمانى

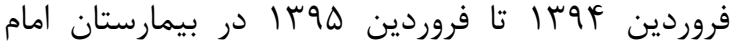
رضاع) تبريز انجام شد، تعداد س V بيمار مبتلا به سروطان

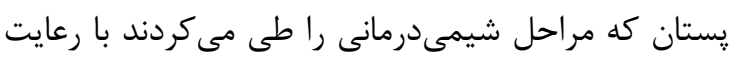
معيارهاى ورود و خروج و به صورت نمونه ديرى در درد دسترس وارد مطالعه شدند. با توجه به اينكه در طول يك

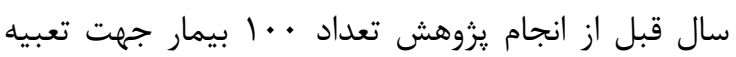

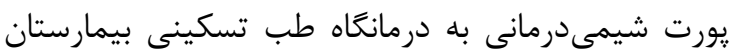

سرطان يستان به عنوان شايعترين سرطان در بين زنان

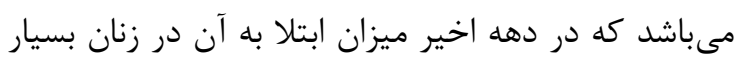

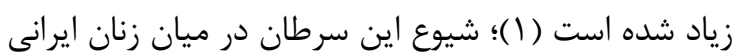

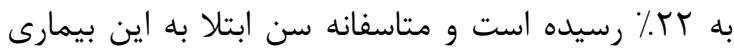

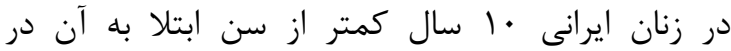

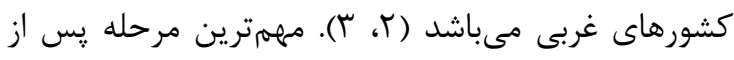

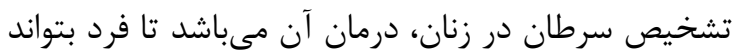

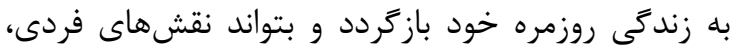

اجتماعى و خانوادىى خود را به انجام برساند (؟).

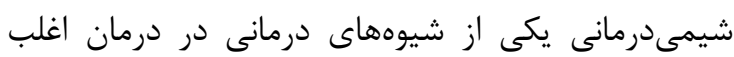
سرطانها و سرطان يستان مىباشد؛ در صورتى كه سرطان فرد در مراحل اوليه تشخيص داده نشود و ابعاد تومور

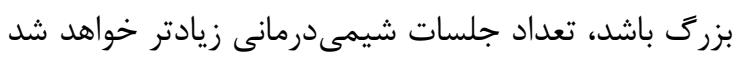
(ه). طولانىتر شدن تعداد جلسات شيمىدرمانى علاوه بر اين كه درمان را كامل كرده و در از بين بردن توداد جانده

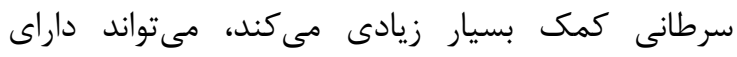
عوارض بسيار زيادى همجون: كاهش كيفيت زندگى بئى بيمار مبتلا به سرطان، افزايش هزينههاى درمانى، افزايش اقامت در بيمارستان، ضعف سيستم ايمنى بدن و افزايش احتمال

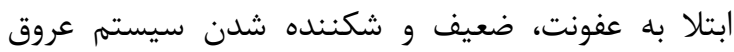
محيطى و افزايش نياز به تعبيه كاتترهاى محيطى مى كردد (Y) (Y) (Y).

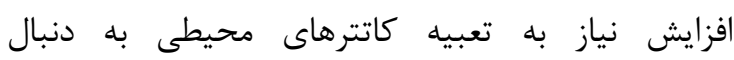
شكنندهتر شدن عروق محيطى در بعضى مواقع تا حدى بـى

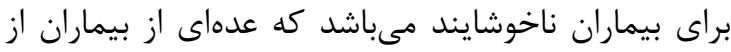

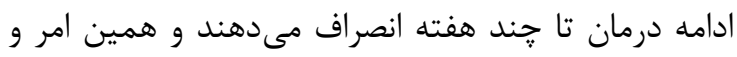

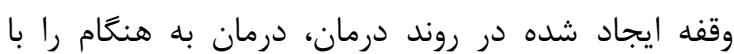

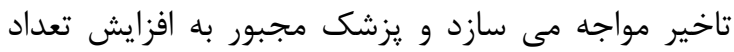

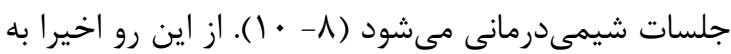

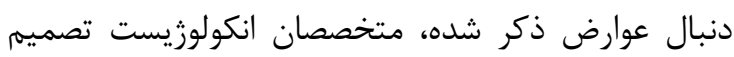

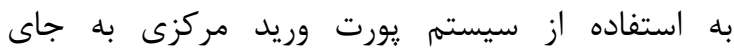
كاتترهاى موقت كَفتهاند. اين سيسته در بيمارانى كه طول دوره درمان طولانى مدت جهت شيمى درمانى دارند، استفاده مىشود. اين سيستم علاوه بر استفاده جهت شيمىدرمانى، جهت تغذيه وريدى، نمونه ئيرى خون، انفوزيون ساير داروهاى مورد نياز بيمار و سرم درمانى نيز

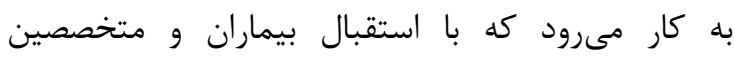
انكولوزى همراه بوده است (1). 


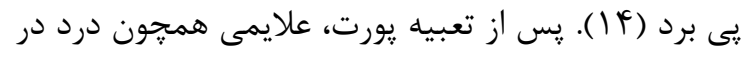

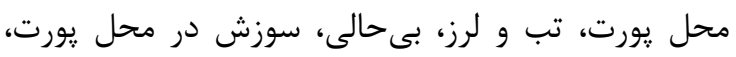

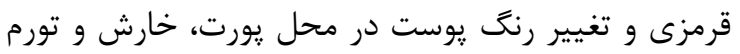
مورد بررسى قرار كرفتند و در صورت مشاهده علايم ذكر دري

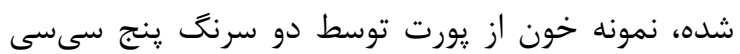

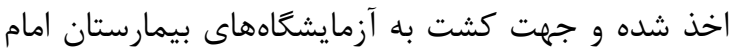

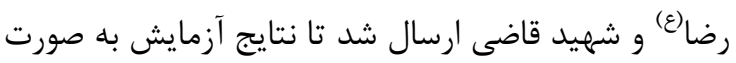

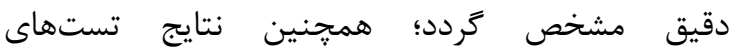
آزمايشكاهى همجحون WBC و ESR جهت تاييد عفونت مورد ارزيابى قرار گرفتند. يس از از اخذ نمون نمانه، مسير يورت

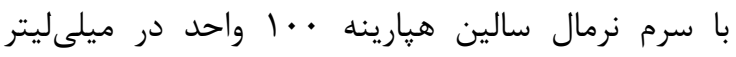
شستشو داده شد و تا زمان دريافت نتيجه، از يورت هيج

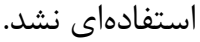

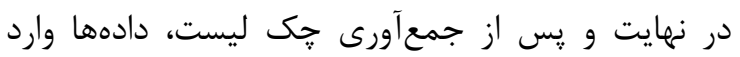
ويرايش 19 نرم افزار آمارى SPSS شدند و براى داده إدهاى

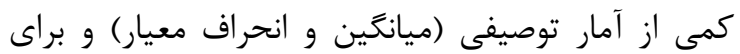
دادههاى كيفى از آزمون Independet t استفاده شد. ميزان P Value به ذكر است عوامل موثر بر تشخيص عفونت محل يورت آنان

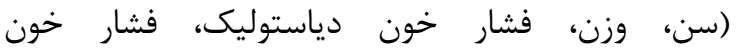

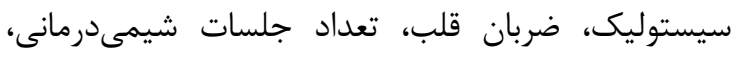
تعداد روزهاى استفاده از يورت، تعداد روزهاى بسترى در تعاد

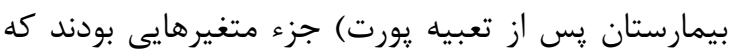
در تجذيه و تحليل وارد شده و مورد بررسى قرار ترفتند. جهت بررسى متغيرهايى همجون فشار خون دياستوليك و سيستوليك، ضربان قلب، تعداد جلسات شيمىدرمانى و Independet t تعداد روزهاى استفاده از يورت از آزماني

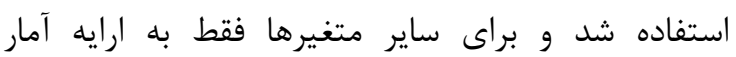

\section{يافته هـا} در اين مطالعه تعداد سץ بيمار مبتلا به سرطان קֶتان كه

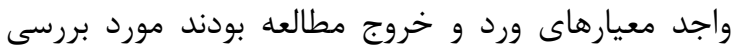

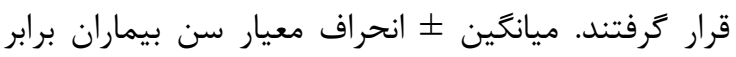

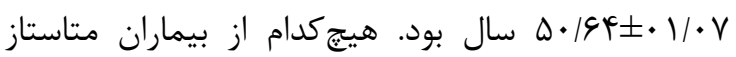
نداشته و به جز ₹ نفر آنان، بقيه داراى تحصيلات متوسطه

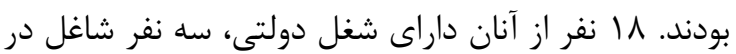
بخش خصوصى و بقيه خانه دار بودند. دو نفر از بيماران نيز در محيط بيمارستان شاغل بودند. 9 نفر از بيماران
امام رضا مراجعه نموده بودند و تنها اين مركز در بين ساير مراكز آموزشى درمانى اقدام به تعبيه يورت مىنمايد،

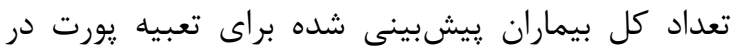

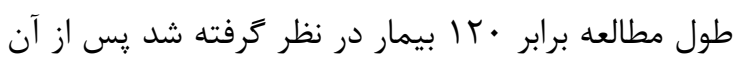

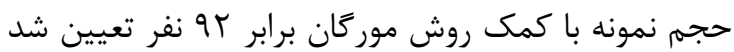
كه از اين تعداد، 19 بيمار به دليل ابتلا به عفونتهاى

سيستميك در طى مطالعه از روند مطالعه خارج شدند. معيارهاى ورود مطالعه شامل: ابتلا به سرطان پِّتان تاييد شده توسط متخصص انكولوزى و متخصص ياتولوزى، انجام حداقل سه مرحله شيمىدرمانى، عدم دسترسى راحت و آسان به وريدهاى محيطى جهت تعبيه كانه كاتترهاى محيطى و معيارهاى خروج از مطالعه نيز شامل: عدم رضايت بيمار به تعبيه يورت، ابتلا به عفونتهاى

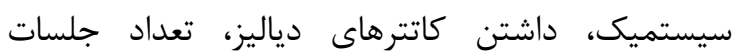
شيمىدرمانى كمتر از شش جلسه بودند. يس از اخذ مجوزهاى مربوطه شامل مجوز كميته

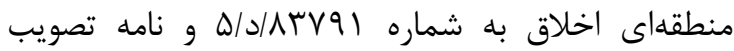

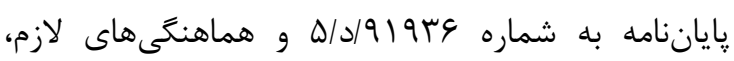
يزوهشكر با در دست داشتن مجوزهاى ذكر شده به واحد

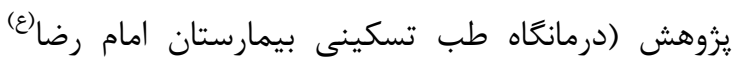

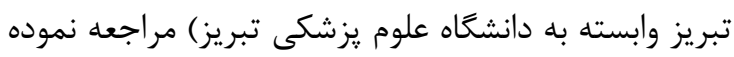

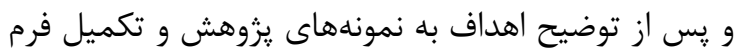
رضايت آكاهانه به صورت كتبى، اقدام به نمونه كيرى نمود. براى تمامى بيماران يورت 4000 - Polysite Standard Series صورت كاملا استريل در اتاق عمل تعبيه شد؛ پيس إز اطمينان از جاى كذارى درست يورت ذكر شده توسط

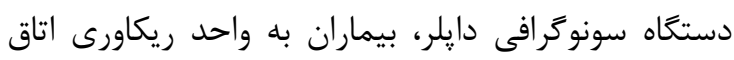
عمل منتقل شده و يس از نيم ساعت اقامت، با وضعيت هموديناميكى پايدار به بخش مربوطه خود منتقل شدند؛

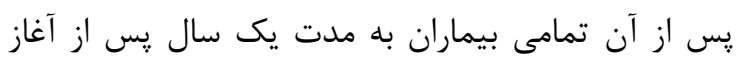
نمونه كيرى مورد بررسى قرار كرفتند. عفونت به ورود، رشد و نمو اركانيسمهاى ميكربى يا انخلى در اندام فرد زنده اطلاق شده كه اين اركانيسمها از بدن بدان

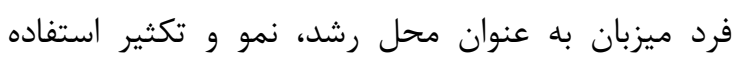

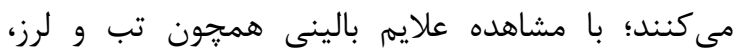
افزايش ضربان قلب، تغيير رنگ يوست، افزايش سطوح

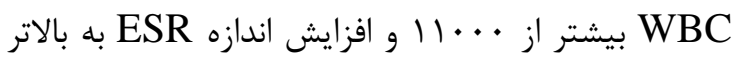

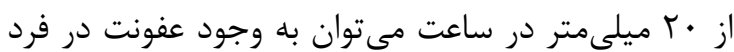


ميانگين (انحراف معيار) فشار خون سيستوليك و واست

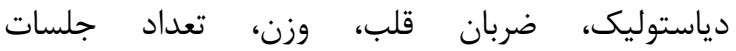
شيمىدرمانى، سن بيماران، تعداد جلسات شيمى درمانى،

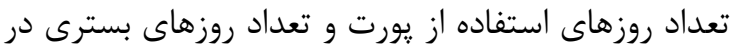

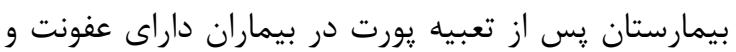
بدون عفونت در جدول شماره r آورده شدهاند.
داراى علايم بالينى عفونت بودند كه يس از نمونهَيرى و بررسىهاى آزمايشگاهى، عفونت 1 نفر تاييد شد (فراوانى عفونت يورت برابر 1٪ بود). علايم مورد بررسى در هر

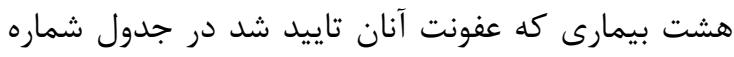

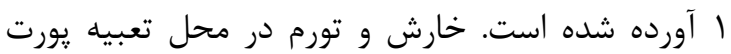
بارزترين علامتى بود كه داراى بيشترين فراوانى بود.

\begin{tabular}{|c|c|c|}
\hline \multicolumn{3}{|c|}{ جدول ا: يافتههاى بالينى نشاندهنده عفونت } \\
\hline 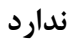 & دارد & 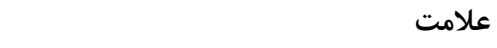 \\
\hline ب انفر & 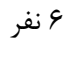 & درد در محل يورت \\
\hline 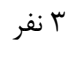 & 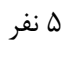 & تب و لرز \\
\hline 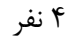 & 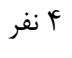 & 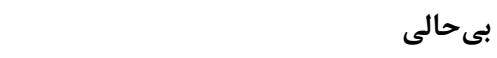 \\
\hline 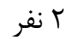 & ك أنفر & سوزش در محل يورت \\
\hline 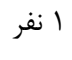 & 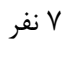 & خارش و تورم در محل يورت \\
\hline 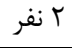 & 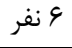 & قرمزى و تغيير رنى يوست در محل يورت \\
\hline
\end{tabular}

جدول r: مقايسه فشار خون، ضربان قلب، وزن و سن و تعداد جلسات شيمىدر مانى تعداد روزهاى استفاده از يورت و تعداد روزهاى

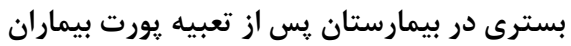

\begin{tabular}{|c|c|c|c|}
\hline P Value & 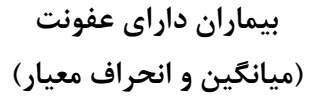 & 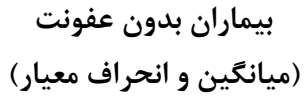 & متغير مورد بر رسى \\
\hline$\cdot / \cdot \mathrm{f}^{2}$ & $\Delta q / F F \pm 1 / \cdot V$ & $F \Delta / \Lambda \cdot \pm \varepsilon / Y \Lambda$ & سن \\
\hline . & $q r / \mid \Lambda \pm r / q)$ & $V T / \Lambda \cdot \pm \Delta / \Delta r$ & وزن \\
\hline - IDTF & $\Lambda r / \Delta r \pm \cdot / G r$ & $\Lambda \mathrm{N} \pm \mathrm{r}$ & فشار خون دياستوليك \\
\hline .1114 & $|r \cdot| 19 \pm 1$ & $\mid Y F \pm V / F \Lambda$ & فشار خون سيستوليك \\
\hline$\cdot|\cdot| f \mid$ & $111 \pm 11 / r T$ & $\Lambda \cdot \mid \mathcal{T}^{\mathrm{T}} \pm 1 / \cdot \mathrm{r}$ & 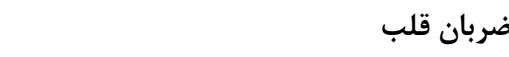 \\
\hline$\cdot 1 \cdot r$ & $V \pm \cdot / \Delta$ & $\Delta \pm 1 / r$ & تعداد جلسات شيمىدرمانى \\
\hline$\cdot 1 \cdot \cdot 1$ & $19 \pm r / r \Delta$ & $F \Delta \pm 1 / \uparrow$ & تعداد روزهاى استفاده از يورت \\
\hline$\cdot 1 \cdot \cdot 1$ & $r \pm \cdot / l r$ & 1 & تعبيد ريورت روزهاى بسترى در بيمارستان يس از \\
\hline
\end{tabular}

سرطانى تا حدود بسيار زيادى موجب تضعيف سيستم

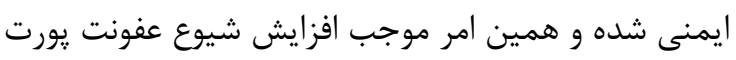

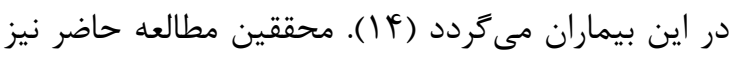
با نظر تيجگَرابر و همكاران مبنى بر افزايش عفونت يورت به دنبال تضعيف سيستم ايمنى در افراد تحت شيمى درمانى هم نظر مىباشند. اريباس و همكاران نيز در مطالعه توصيفى مقطعى خود مانى شيوع عفونت محل يورت در بيماران تحت شيمى إرمانى رانى كه تعداد كل نمونههاى شركت كننده در مرلت مطالعه آنان آ| بيمار بود با استفاده از جك ليستى مشابه مطالعه حاضر، حدود V٪ بيان كردند كه با شيوع نسبى آن در لرد
هدف از انجام اين مطالعه بررسى شيوع و عوامل

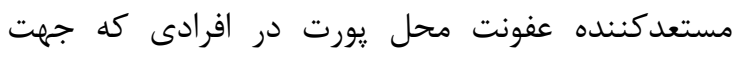
شيمىدرمانى در آنان يورت ساب كلاوين تعبيه شده بود، مى باشد. شيوع عفونت محل يورت در مطالعه ما برابر • 1\% مىباشد كه بيشتر از نتايح مطالعه مرورى تيجگًرابر و همكاران مىباشد؛ آنان در مطالعه مرورى خود با بررسى مطالعات

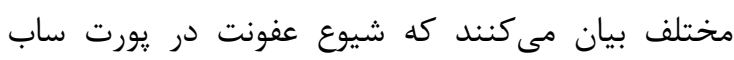

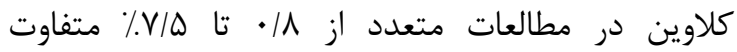
مىباشد؛ محققين معتقدند شيمىدرمانى در مبيماران 
توره و همكاران نيز در مطالعه توصيفى همبستخى خود إنا

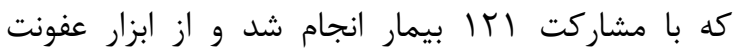
سنجى دانشعاه ليون فرانسه در مطالعه خود استفاده

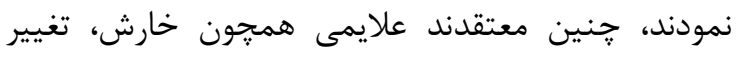

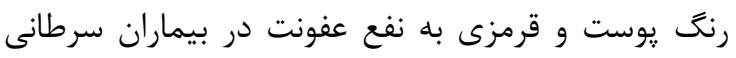
عمل مى كنند؛ همجنين آنان معتقدند در افراد سرطانى كه تحت شيمىدرمانى هستند، با توجه به اينكه داروهاى شيمىدرمانى موجب تضعيف سيستم ايمنى مئى ندوند، توجه بيشتر به علايم بالينى عفونت نسبت به بقيه بيماران

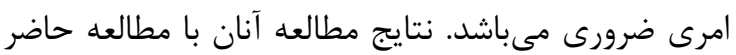

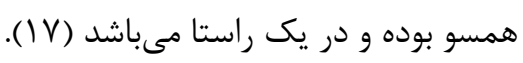
ميان تعداد جلسات شيمى درمانى در دو گروهى كه داراى عفونت هستند و كروهى كه عفونت نداشتند ارتباط مشاهده شد، به نحوى كه در افرادى كه تعداد جلسات

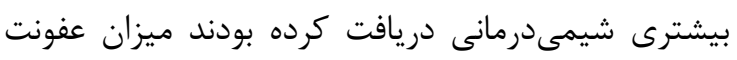
بيشتر مشاهده شد. به نظر مىرسد با دريافت داروهاى

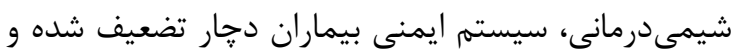
همين امر آنان را مستعد انواع عفونت از جمله عفونت إندان

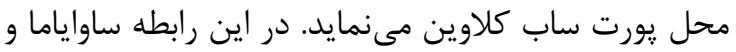

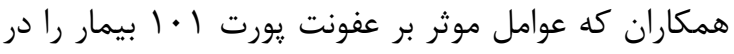

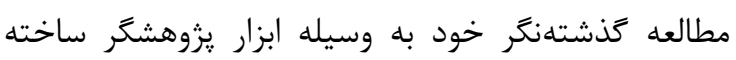

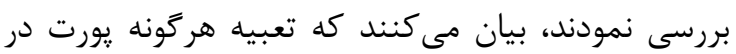
بيمارانى كه داراى سيستم ايمنى ضعيف هستند از جمله

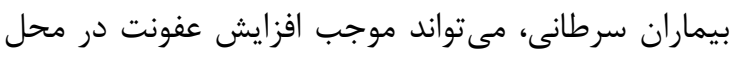
تعبيه شود. نتايج مطالعه آنان با نتايج مطالعه موانه حاضر همسو

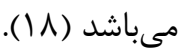
در مطالعه حاضر مشخص شد كه بيمارانى كه روزهاى كمترى از يورت استفاده كرده اند نسبت به بيمارانى كه مدت زمان بيشترى از آن استفاده نمودهاند بيشتر دهار

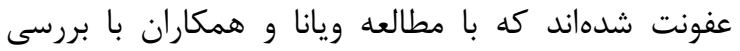
كذشتهنكر يرونده شيمىدرمانى استفاده كرده بودند، همسو نبوده و در يك بكرئ

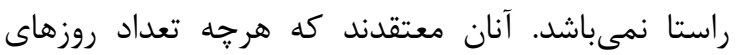

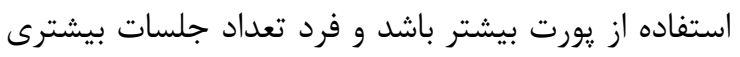

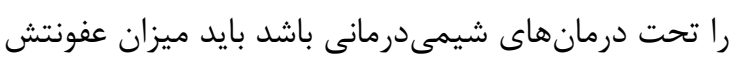

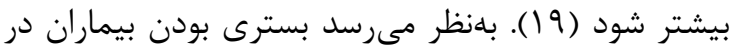

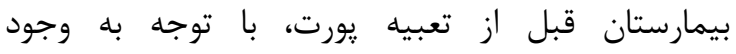

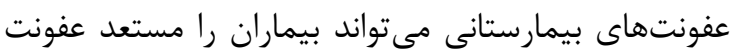

ساير مطالعات همسو بود در حالى كه نسبت به مطالعه حاضر داراى درصد يايينى بوده و در يك راستا نمىباشد

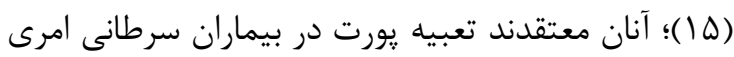

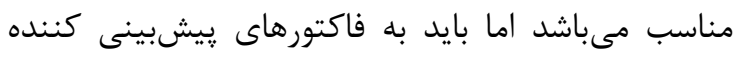
عفونت در آنان توجه نمود تا از ابتلا به عفونت محل يورت آنايد

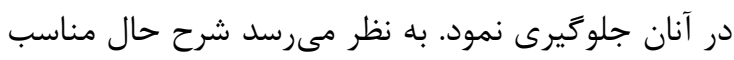

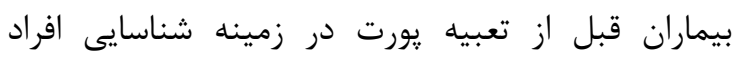

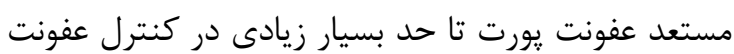
آن كمك كننده مىباشد. ليوباخ و همكاران نيز در مطالعه خود ميزان عفونت مرتبط

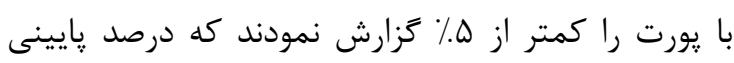

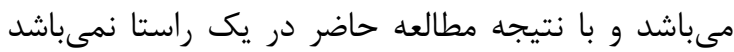

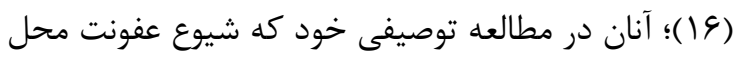

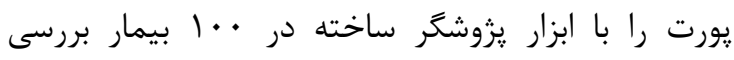

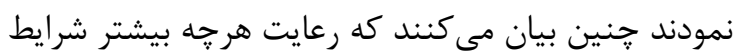
استريل زمان تعبيه يورت و وانسمان اوليه آن از مهمهترين

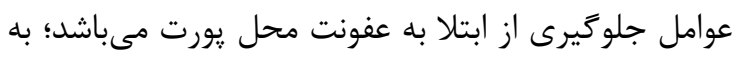
نظر مىرسد شرايط زمان تعبيه يورت در كنار عوامل ثانويه

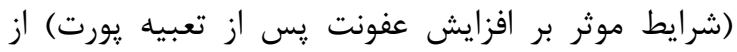

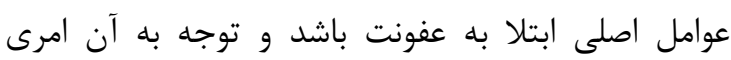
حياتى مى باشد. بررسى نتايج حاكى از آن است كه درد در محل يورت، سوزش در محل يورت، خارش و تورم در محل يورت،

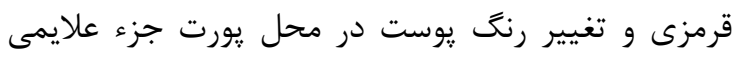
هستند كه در بيماران داراى عفونت تاييد شده توسط تستهاى آزمايشكاهى داراى بيشترين فراوانى مىباشد.

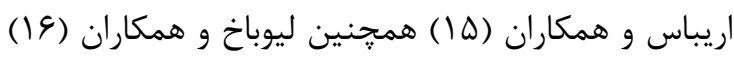

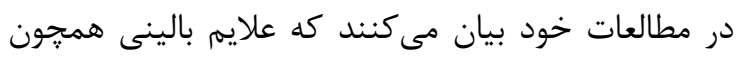
سوزش و تورم در محل تعبيه يورت، خارش و قرمزى در محل يورت از علايمى هستند كه به نفع عفونت عمل

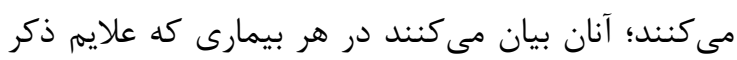

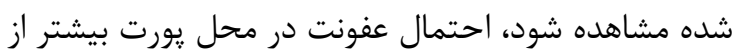

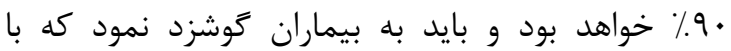

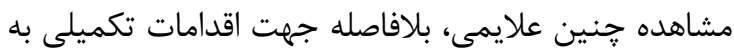

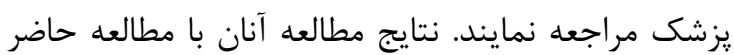
همسو مىباشد. به نظر مىرسد به علايمى همجِون خارش، براند درد، تورم و قرمزى كه از علايم ثابت عفونت مى بـاشند بايد

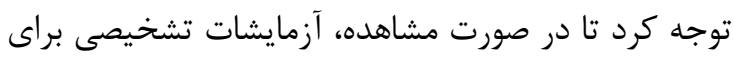

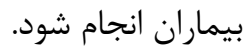


بيمارستان در طول مطالعه آنان مورد بررسى قرار گرفته

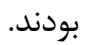
קإيين بودن حجم نمونه به دليل محدوديت مالى - زمانى و

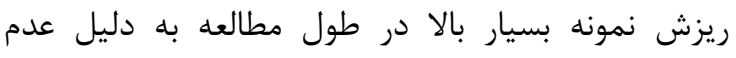

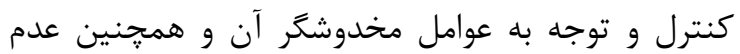
بررسى نوع عفونت و سوشهاى باكتريايى آن به عنوان نقاط ضعف مطالعه حاضر مىباشد. محققين يِيشنهاد مى كنند در مطالعات بعدى نوع عفونت محل تعبيه يورت

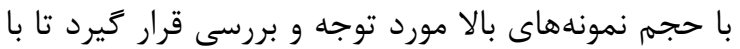
تكيه بر نتايج آن بتوان اقدامت مههمتر و يِيشخيرانه را اتخاذ

\section{نتيجه نيرى}

شيوع حدود · ا درصدى عفونت محل يورت در بيماران

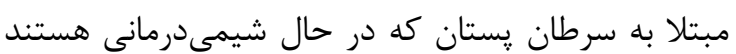

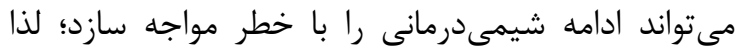
توجه به فاكتورهاى موثر در افزايش احتمال ابتلا به عفونت

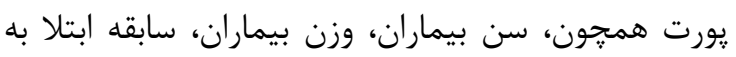

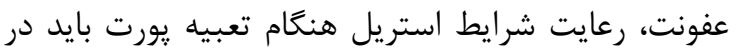

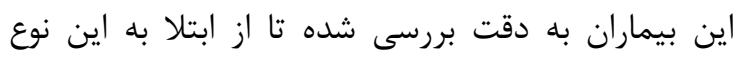

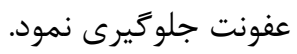

\section{تشكر و قدردانى}

اين مقاله حاصل نتايج قسمتى از ياياننامه خانم مرضيه جعفرى جهت اخذ مدرى دكتراى حرفهاى يزشكى إنى

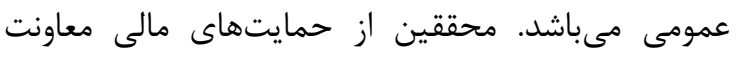

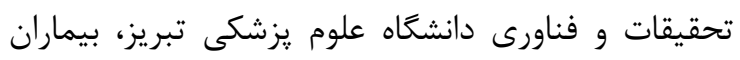

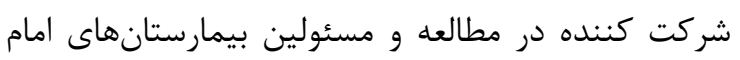

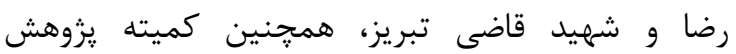

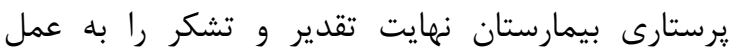

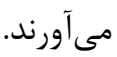

\section{References}

1. DeSantis C, Jiemin M, Leah B, Ahmedin J. Breast cancer statistics, 2013 . Dent Traumatol 011; 27(2):131-4.

2. Singh V, Malkunje L, Mohammad S, Singh N, Dhasmana S, Das SK. The
نمايد؛ البته جنين دليلى بهتر است در ساير مطالعات به

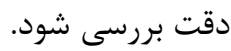
در مطالعه حاضر بين افزايش سن و كاهش وزن با ابتلا به عفونت يورت ارتباط مستقيم و معنى دار مشاهده شد؛ ساواياما و همكاران در مطالعه خود همجيون نتايج مطالعه حاضر ارتباط مستقيمى بين افزايش سن، كاهش وزن و وان إنات احتمال افزايش عفونت محل يورت مشاهده نمودند؛ آنان

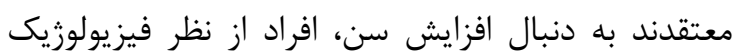
ضعيف شده و در صورتى كه به سرطان مبتلا شوند ضعف و كاهش وزن آنان بيشتر و سريعتر نمود يِيدا كرده،

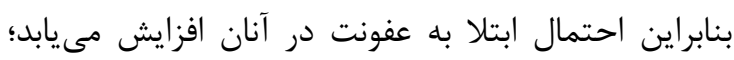

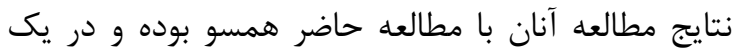
راستا مىباشد (1) (1).

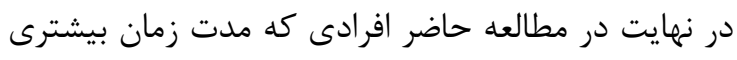
را پس از تعبيه يورت در بيمارستان بسترى بودند نسبت

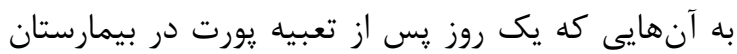
بسترى بودند، بيشتر دجار عفونت شدند؛ به نظر مئرسا

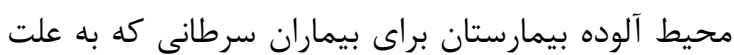
شيمىدرمانى دجار تضعيف سيسته ايمنى شدهاند مى تواند

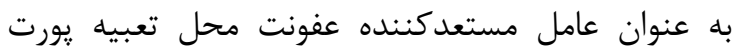

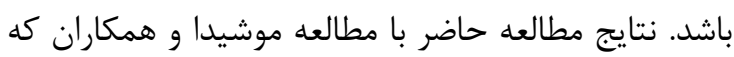

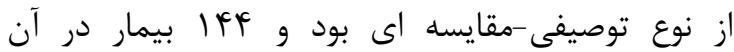
مشاركت داشتند و علايم بالينى بيمارانى كه از يورت تورات

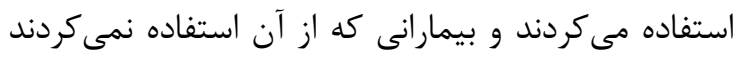
به كمك ابزار مورد استفاده در ساير مطالعات مشابه سنجيده شد، همسو مىباشد (•r). كلجبينى و همكاران

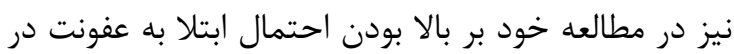

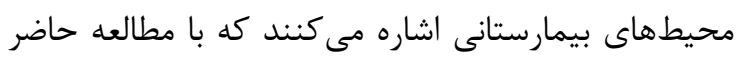
همسو مىباشد (II). لازم به ذكر است در مطالعات موشيدا و همكاران و كلجبينى و همكاران كه هر دو از نوع التهان

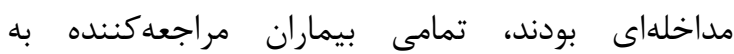

maxillofacial injuries: A study. Natl J Maxillofac Surg 2012; 3(2):166-9.

3. Gutta R, Tracy K, Johnson C, James LE, Krishnan DG, Marciani RD. Outcomes of mandible fracture treatment at an academic 
tertiary hospital: A 5-year analysis. J Oral Maxillofac Surg 2014; 72(3):550-8.

4. Jung H-W, Lee B-S, Kwon Y-D, Choi B-J, Lee J-W, Lee H-W, et al. Retrospective clinical study of mandible fractures. $\mathrm{J}$ Korean Assoc Oral Maxillofac Surg 2014; 40(1):21-6.

5. Lucca M, Shastri K, McKenzie W, Kraus J, Finkelman M, Wein R. Comparison of treatment outcomes associated with early versus late treatment of mandible fractures: a retrospective chart review and analysis. $\mathrm{J}$ Oral Maxillofac Surg 2010; 68(10):2484-8.

6. Yeo MS, Goh TL, Nallathamby V, Cheong EC ,Lim TC. Maxillary artery injury associated with subcondylar mandible fractures: a novel treatment algorithm. Craniomaxillofac Trauma Reconstr 2012; $5(2): 83-8$.

7. Vázquez-Morales DE, Dyalram-Silverberg D, Lazow SK, Berger JR. Treatment of mandible fractures using resorbable plates with a mean of 3 weeks maxillomandibular fixation: a prospective study. Oral Surg Oral Med Oral Pathol Oral Radiol Endod 2013; 115(1):25-8.

8. Pena Jr I, Roberts LE, Guy WM, Zevallos JP. The cost and inpatient burden of treating mandible fractures: a nationwide inpatient sample database analysis. Otolaryngol Head Neck Surg. 2014;151(4):591-8.

9. Barker DA, Park SS. Is fixation of mandible fractures urgent? Laryngoscope 2011; 121(5):906-7.

10. Chrcanovic BR, Abreu MHNG, FreireMaia B, Souza LN. 1,454 mandibular fractures: a 3-year study in a hospital in Belo Horizonte, Brazil. Journal of CranioMaxillo- Facial Surgery 2012; 40(2):11623.

11. Otto S, Troeltzsch M, Burian E, Mahaini $S$, Probst $F$,Pautke $C$, et al. Ibandronate treatment of diffuse sclerosing osteomyelitis of the mandible: Pain relief and insight into pathogenesis. Journal of Cranio-Maxillo-Facial Surgery 2015; 43(9):1837-42.

12. Theunissen M, Peters ML, Bruce J, Gramke H-F, Marcus MA. Preoperative anxiety and catastrophizing: a systematic review and meta-analysis of the association with chronic postsurgical pain. Clin J Pain 2012; 28(9):819-41.

13. Kim SY, Jeong JJ, Chung WY, Kim HJ, Nam K-H, Shim YH. Perioperative administration of pregabalin for pain after robot-assisted endoscopic thyroidectomy: a randomized clinical trial. Surg Endosc 2010; 24(11):2776-81.

14. Teichgräber, Ulf KM, Kausche, Stephan, Nagel, Sebastian N, Gebauer, Bernhard. Outcome analysis in 3,160 implantations of radiologically guided placements of totally implantable central venous port systems. European radiology 2011; 21(6): 1224-32.

15. Aribaş B K, Arda K, Aribaş Ö, Çiledağ N, Yoloğlu Z, Aktaş E \& et al. Comparison of subcutaneous central venous port via jugular and subclavian access in 347 patients at a single center. Experimental and therapeutic medicine 2012; 4(4): 675-80.

16. Lebeaux D, Fernández-Hidalgo N, Chauhan A, Lee S, Ghigo JM, Almirante B \& et al. Management of infections related to totally implantable venous-access ports: challenges and perspectives. The Lancet infectious diseases 2014; 14(2): 146-59.

17. Touré A, Vanhems P, Lombard-Bohas C, Cassier P, Péré-Vergé D, Souquet JC \& et al .Totally implantable central venous access port infections in patients with digestive cancer: incidence and risk factors. American journal of infection control 2012; 40(10): 935-9.

18. Sawayama H, Hayashi N, Watanabe M, Takamori H, Beppu T, Baba H. The central vein access port and catheter in outpatient chemotherapy for colorectal cancer: a retrospective study of 101 patients. Surgery today 2012; 42(1): 29-34.

19. Viana T, Michelle Ribeiro L, Luciana A, Cláudia M, Maria G . Risk factors for central line-associated bloodstream infection in pediatric oncology patients with a totally implantable venous access port: A cohort study. Pediatric blood \& cancer 2017; 64(2): 336-42.

20. Yoshida Y, Hoshino, Seiichiro A, Naoya N, Masayasu T, Syu M, \& et al. 
Administration of chemotherapy via the median cubital vein without implantable central venous access ports: port-free chemotherapy for metastatic colorectal cancer patients. International journal of clinical oncology 2015; 20(2): 332-7.
21. Goljabini S, Farzin H, Khanbabayi Gol, M. The effect of clinical-based clinical training on nurses'performance in the prevention of ventilatorassociated pneumonia in special wards of urmiaeducational centers in night shift. The J Urmia Nurs Midwifery Fac 2018; 15(11): 843-50. 